\title{
Analysis of Permanent Housing Built after Disaster: Van (Turkey)
}

\author{
Sinan ÖZTAŞ, Gökay AKKAYA
}

\begin{abstract}
In 2011, 644 people passed away after two earthquakes struck the city of Van, located in eastern Turkey. Houses collapsed or were rendered uninhabitable. Thousands of people became homeless. In response, the government built 17489 units of permanent housing in a standard size and type. This study determined a more effective housing allocation for earthquake victims by considering the types of households (one-person households, one-family households, extended-family households and multi-person, no family households) and the total available housing area as allotted by the government's relief building budget. The Analytic Hierarchy Process was used to prioritize home features for each type of household. These results showed that housing size tailored to household need was more important than price, location or design. Mathematical modeling was then used to identify housing space allocations that would serve family needs better than a uniform building approach.
\end{abstract}

Keywords: permanent housing; disaster operations management; mathematical modelling; analytic hierarchy process

\section{INTRODUCTION}

Studies in the field of disaster management can be divided into four categories: mitigation, preparedness, response and recovery. While recovery represented $12 \%$ of all disaster activities according to a literature study carried out in 2006 [1], this rate was lowered to $5 \%$ in a later 2013 study [2]. The low and decreasing percentage of recovery activities indicates that sufficient time and resources are not being allocated to this critical aspect of disaster management.

Issues related to assigning temporary housing (such as tents or containers) are studied more often than those related to the assignment of permanent housing. This may be because most countries do not have uniform standards for disaster relief construction of permanent housing. Therefore, this study addresses the problem of assigning areas of permanent housing.

First, the Analytical Hierarchy Process (AHP) was used to explore the importance of several factors to family households of varying size. Next, the relationship between the number of individuals in the family and home size was evaluated by correlation analysis. Finally, mathematical modeling was used to identify new types of housing allocation.

\subsection{Permanent Housing built by the Government}

Turkey is accustomed to the unpleasant reality of natural disasters. The location and size of large-scale earthquakes that have occurred in Turkey are shown in Fig. 1.

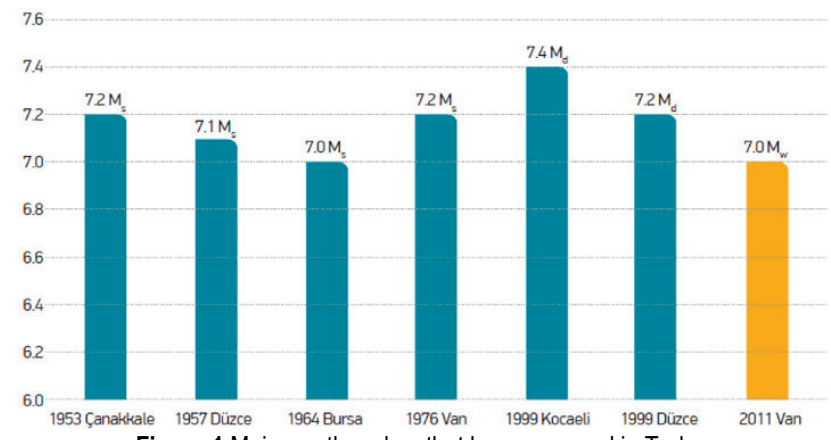

Figure 1 Major earthquakes that have occurred in Turkey
A common earthquake culture has developed in Turkey. Disaster planning and relief has been led by state organs. After the immediate first aid, search and rescue activities are completed, the most important need is housing, particularly in the wake of major earthquakes. Temporary housing areas using tents or containers are primarily built with assistance from the government and non-governmental organizations. The needs of the disastervictims and the construction of permanent housing become a priority only after communities have recovered from the shock of the earthquake and the search and rescue activities have been exhausted.

After the 2011 earthquake in Van, Turkey left tens of thousands of people homeless, the government decided to build permanent housing for the victims. With guidance from specialists, new home sites were quickly identified. The construction was completed under difficult conditions, given the region's heavy winters. Within a year, new homes began to be distributed to the earthquake victims.

The houses were all planned and built to be the same size $\left(99.5 \mathrm{~m}^{2}\right.$ gross). Each unit included the same number and type of rooms (a traditional Turkish house of three bedrooms and a living room). The homes were distributed to the owners by lot. The homes built for the disaster victims in Van are shown in Fig. 2 below.

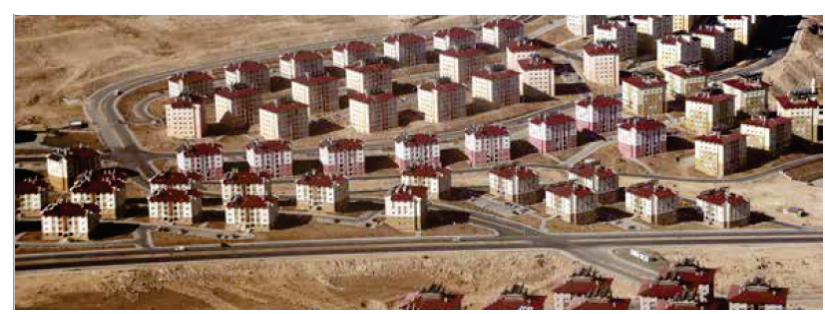

Figure 2 The permanent houses built for the disaster victims in Van

The government built 17489 homes. Each unit has a gross area of $99.5 \mathrm{~m}^{2}$. This corresponds to a total housing area of $17489 \times 99.5=1740155.5 \mathrm{~m}^{2}$.

\subsection{Recommended Permanent Housing}

The Turkish Statistical Institute divides Turkish families into four groups: one-person households, onefamily households, extended-family households and multi- 
person, no family households. Tab. 1 shows the average family sizes in Turkey (the country as a whole) and in Van for the last five years Family sizes are calculated based on the average number of individuals in the family [3].

Table 1 Average family size in Turkey and Van (as number of people)

\begin{tabular}{|l|c|c|c|c|c|}
\hline & 2012 & 2013 & 2014 & 2015 & 2016 \\
\hline Van & 6.4 & 6.0 & 5.8 & 5.8 & 5.3 \\
\hline Turkey & 3.7 & 3.6 & 3.6 & 3.5 & 3.5 \\
\hline Ratio (Van/Turkey) & 1.73 & 1.67 & 1.61 & 1.66 & 1.51 \\
\hline
\end{tabular}

For the last five years, the average family size in Van has been above the average in Turkey. Moreover, for each of these years, the family size in Van is at least one and a half times higher. There are also regional differences in the distribution of household types. Tab. 2 provides a breakdown of the types of family households in Turkey and Van as published by the Turkish Statistical Institute in 2016 [3].

Table 2 Types of family households in Turkey and Van

\begin{tabular}{|c|c|c|c|c|c|}
\hline & ت্ّ & 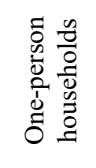 & 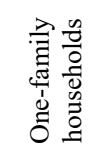 & 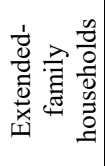 & 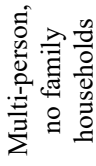 \\
\hline Van & 201722 & 17807 & 131707 & 48275 & 3933 \\
\hline Turkey & 22206776 & 40449 & 181955 & 44650 & 6603 \\
\hline $\begin{array}{c}\text { Ratio } \\
\text { (Van/Turkey) }\end{array}$ & & 0.44 & 0.72 & 109 & 060 \\
\hline
\end{tabular}

In Turkey, the average number of persons living in one-person households was one; the average number of persons living in one-family households was four; the average number of persons living in extended-family households was six; and the average number of persons living in multi-person, no family households was two [3].

The ratios presented in Tab. 2 illustrate that the number of extended-family households in Van is above the average for Turkey, while one-person households and multiperson, no family households in Van are far below the average for Turkey. Consequently, families living in Van are more often part of extended-family households than families living in the rest of Turkey.

As can be understood from these two tables, the standard uniform homes constructed by the government are not functional for the earthquake victim families in Van. The distribution of household types in Van is different than that for Turkey as a whole, and the average family size in Van is one and a half times higher than that of Turkey.

To explain further, it is illogical to construct homes of the same size for one-person households and for multiperson, no family households consisting of at least six people. This system makes it difficult for families, especially children, to return to a normal social life.

For the above-mentioned reasons, it would be preferable for families to live in homes whose square footage reflects the number of family members. A more practical allocation of housing will accelerate the ability of disaster victims, particularly children, to adapt to their new post-disaster lives.

To address this problem, this study identified a more appropriate allocation of home sizes for the four types of family households. In this analysis, the total housing area did not exceed the $1740155.5 \mathrm{~m}^{2}$ previously budgeted for the Van earthquake victims so that construction costs should be similar to that of the standard unit housing that has already been built. Housing size was determined using a mathematical model to calculate the optimal area $\left(\mathrm{m}^{2}\right)$ for each home, after a fixed common living area (toilet, bathroom, corridor and hall) was determined.

Table 3 The rate and number of houses distributed to the disaster victims by the government

\begin{tabular}{|c|c|c|c|c|c|}
\hline & \multirow[b]{2}{*}{ Total } & \multicolumn{4}{|c|}{ Types of families } \\
\hline & & 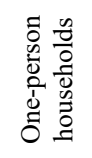 & 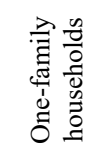 & 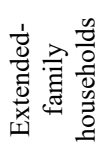 & 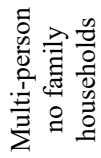 \\
\hline $\begin{array}{c}\text { Number of } \\
\text { Families }\end{array}$ & 201722 & 17807 & 131707 & 48275 & 3933 \\
\hline $\begin{array}{c}\text { Rate of } \\
\text { Distributed } \\
\text { Houses }\end{array}$ & 1 & 0.088 & 0.653 & 0.239 & 0.019 \\
\hline $\begin{array}{c}\text { Number of } \\
\text { Distributed } \\
\text { Houses }\end{array}$ & 17489 & 1545 & 11426 & 4184 & 334 \\
\hline
\end{tabular}

Tab. 3 shows the distribution of state-built housing to family types in Van. Houses were distributed to families in proportion to their family numbers.

\section{LITERATURE SURVEY}

In the post-disaster recovery works, the following topics are included: determination of temporary house (tent city, container city) areas, assignment of people to these houses, determination of meeting areas, collection of piles of debris, delivery of emergency basic human needs after disaster, determination of the possible routes to be used after the disaster, providing telephone therapy to disaster victims, assignment of disaster victims to permanent houses by taking into account various priorities, determination of warehouse and distribution points, appointment of health personnel and scheduling, determination of the routes of prior vehicles such as fire brigade, ambulance and police vehicle and other topics etc.

Altay and Green examined all the publications in the field of disaster operations management, which are included in the literature and can be reached, in the study they carried out in 2006 about the relevant year. In this study, they examined the subjects in the disaster in four main topics as relieving, preparedness, intervention and improvement. The topics such as in which fields the publications were included, in which magazines they were published, which mathematical approach was used were examined. As a result of this study, it was seen that the least worked part of the disaster operation management field was the improvement stage as about $12 \%$ [1].

Galindo and Batta carried out a similar study of the literature research in 2013. [1]'s methods were followed as a flow in the study. This time the study was expanded in the direction of operational research and management science in disaster operations management. In the study, it was researched in which journals, in which areas, in which rate and in which methods the publications were made. As a result of this study, it was seen that post-disaster recovery works were carried out as 5\% in all studies [2].

Hasanzadeh and Bashiri worked on modelling the humanitarian aid logistics network. Covering location problem and hub location problems were discussed in the 
study. Lagrangian relaxation was used to find the lower limit for solving bigger problems [4].

Najafi et al. recommended a multipurpose agile optimization model for efficient logistics planning at the time of the intervention. After an earthquake, data sources are short and inadequate, so they recommended a multipurpose, multi-mode, multi-period dynamic approach to intervene effectively [5].

Rakes et al. aimed to assign the families to temporary houses after the disaster by taking various criteria into account such as education and health, with the help of the decision support system they have developed. Discrete mathematical modelling and heuristic methods were used in the study [6].

Keeping in mind the earthquake that occurred in Chile in 2010, Galarce et al. developed a mathematical model that enables disaster victims to be directed to places where they can take shelter, receive medical treatment and have psychotherapy [7].

In their study, Gregorio and Soares have developed an approach to the problems of housing in the framework of post-disaster recovery in developed countries bearing in mind the US experience. Considering the developed countries, there are suggestions in the study concerning housing problems [8].

Joshi and Nishimura have worked on the communication between the government and the disaster victims for post-disaster housing works taking into account the tsunami that took place in 2004 in the Indian Ocean. Subjects such as material and financial aid to these disaster victims are present in the communication network [9].

Dikmen and Özkan have done studies on whether the new houses that the government had built after the disaster were appropriate for human needs. The matter of how well the houses that the government had built and the traditional houses that they recommended meet the needs was discussed in their study by using a variance analysis [10].

Othman and Beydoun have worked together on information sharing in disaster management. They have developed a system that gathers all the information and enables the users to access easily [11].

In their study, Fikar et al. have established a decision support system for the post-disaster humanitarian aid operations. A mixed integer mathematical model and a factor-based simulation were utilized in this study. The study was built on the incidents that took place in Austria and the results were obtained accordingly [12].

Onan et al. have studied building a new framework to determine the locations of temporary storage facilities, planned for the collection and transportation of disaster waste in order to manage it in an environmentally sustainable way. In this study, a multi-objective optimization model is developed and solved with an evolutionary elitist multi-objective optimization algorithm (NSGA-II) by them [13].

Labib and Read have studied the Hurricane Katrina disaster in 2005. They used Fault Tree Analysis (FTA), Reliability Block Diagram (RBD), Risk Priority Number (RPN) and Analytic Hierarchy Process (AHP) together as the methodology. They used AHP for a simulation model for the decision support [14].

Zhang et al. have worked on wind disaster emergency problem. They have studied the subject with only a little information and because of that, they have used grey relational analysis for getting more info. In addition, they put multi-objective genetic algorithm and grey method together in this study [15].

Raikes \& McBean argue that a lack of standards in emergency management legislation, restrictive access to financial assistance and/or compensation and reduced government exposure to civil liability a common law expose private land owners to greater vulnerability to disasters and the liability attached [16].

Erd et al. have studied the design and implementation of a wireless sensor network which has ultrasonic ability and self feeding for an emergency scenario [17].

Purpose of the paper published by Silovs et al. are Latvian wind related disasters. The study aims to analyse methods and preventions of wind-related disasters. There is no mathematical model or solution but there are some suggestions about disasters [18].

Wex et al. have aimed to minimize the total response time for a disaster. For this purpose they develop a corresponding decision support model. The problem is NPhard and they use some kind of heuristic methods to solve it [19].

Caymaz et al. have proposed in their work to focus on post disaster operations specific to Turkey. They try to make a strategic way to prevent human deaths and other national assets [20].

Akkaya et al. have studied the sector selected for industrial engineering students by using fuzzy Ahp and fuzzy Moora. The study aims to define the most selectable jobs for students and graduate people [21].

\section{METHODOLOGY}

\subsection{Analytic Hierarchy Process}

The Analytical Hierarchy Process (AHP) is a decisionmaking technique developed by Thomas Saaty in 1971 and widely used in the literature since 1980 [22]. AHP enables the selection of the best among several alternatives (indicated by the highest score) in which the weight (significance) of each criterion is determined by making binary comparisons of several criteria. Tab. 4 shows Saaty's binary comparison matrix.

Table 4 Saaty's binary comparison matrix

\begin{tabular}{|c|l|}
\hline Value & \multicolumn{1}{c|}{ Statement } \\
\hline 1 & Equally important \\
\hline 3 & Slightly more important \\
\hline 5 & More important \\
\hline 7 & Strongly more important \\
\hline 9 & Absolutely more important \\
\hline $2,4,6,8$ & Express intermediate values \\
\hline
\end{tabular}

If the values determined from the binary comparison produce matrix $\boldsymbol{A}$, the normalized binary comparison matrix obtained from this matrix is expressed as A norm. The value is obtained by dividing each value in the columns by the column sum and is calculated by the following equation:

$\bar{a}_{j k}=\frac{a_{j k}}{\sum_{l=1}^{m} a_{l k}}$

where $m$ is the number of compared criteria. Weights are calculated by dividing the $w$ column vector by the $m$ value. The weight (significance) grades of the criteria are 
determined by ranking the obtained values from lowest to highest:

$$
w_{j}=\frac{\sum_{l=1}^{m} \bar{a}_{j l}}{m}
$$

After this step, the criterion with the greatest value is regarded as the most important criterion, and the significance of the other criteria can be evaluated.

In our study, there were four main criteria and three sub criteria. The main criteria were location, design, size and price. The sub criteria for location were near school, near hospital and near relatives. The sub criteria for design were high level, medium level and poor level. The sub criteria for size were large size, medium size and small size. The sub criteria for price were cheap price, medium price and expensive.

The disaster victims were asked to rank the main and sub criteria using an online questionnaire. Participants were earthquake victims who live in the government housing that was constructed to a standard size and style.

The results of the survey and the AHP analysis are summarized in Tab. 5. The main criteria were ranked as follows: size, price, location and design.

Table 5 Results of AHP

\begin{tabular}{|l|c|c|c|c|c|}
\hline & Level 1 & Level 2 & Level 3 & Total & Rank \\
\hline Location & 0,095 & 0,029 & 0,009 & 0.133 & 3 \\
\hline Design & 0,032 & 0,0077 & 0,0043 & 0.044 & 4 \\
\hline Size & 0,325 & 0,131 & 0,0535 & 0.509 & 1 \\
\hline Price & 0,229 & 0,059 & 0,026 & 0.314 & 2 \\
\hline
\end{tabular}

\subsection{MATHEMATICAL MODEL AND SOLUTION}

Given the results of the AHP analysis, a mathematical model was designed to determine a more optimal housing allocation. The following assumptions were used to set up the model.

Assumptions: The government built 17489 houses that were distributed to Van earthquake victims in accordance with the type of household.

As seen in Tab. 3, out of 17489 houses, 1545 were distributed to one-person households, 11426 were distributed to one-family households, 4184 were distributed to extended-family households and 334 were distributed to multi-person, no family households.

The following parameters were used to design the mathematical model. The space needed for each household's communal area was determined. This communal area comprises functional space that is not dependent upon the number of people in the family, for example, a bathroom or a hall. Our study determined that the total communal area for each household type should be $20 \mathrm{~m}^{2}$. This fixed communal area was subtracted from the total available housing area to calculate a total variable housing area.

Total housing area: $1740155.5 \mathrm{~m}^{2}$

Total fixed area: $20 \times 17489=349780 \mathrm{~m}^{2}$

Variable Housing Area:

$1740155.5-349780=1390375.5 \mathrm{~m}^{2}$

\section{Notations and formulations}

$i$ - Family type

$a_{i}$ - Number of persons in the $i$ type family

$c_{i}$ - Size of the $i$ type house

$x_{i}$ - Total number of $i$ type families that have been appointed

Objective function:

$\max z=\sum_{i=1}^{I} \frac{c_{i}}{a_{i}}$

Constraints:

$\sum_{i=1}^{n} x_{i} c_{i=1390375.5}$

$2 a_{1}=a_{2}$

$4 a_{1}=a_{3}$

$6 a_{1}=a_{4}$

Eq. (3) sets forth that the housing size divided by the number of people must be equal and max for all housing types.

Eq. (4) represents the remaining variable field after the constant field is subtracted, which must be equal to the total variable field of the housing types.

In the constraint expressed by Eq. (5), $a_{1}$ stands for type 1 (one-person households), $a_{2}$ stands for type 2 (multiperson, no family households), $a_{3}$ stands for type 3 (onefamily households), and $a_{4}$ stands for type 4 (extendedfamily households). The ratios between the equations and each other were qualified. The mathematical model was solved using Excel solver and the results were tabulated in the respective categories.

Table 6 Comparison and results of Housing zone

\begin{tabular}{|c|c|c|c|c|c|}
\hline & \multirow{2}{*}{$\begin{array}{c}\text { Total } \\
\mathrm{m}^{2}\end{array}$} & $\begin{array}{c}\text { One-person households } \\
\mathrm{m}^{2}\end{array}$ & $\begin{array}{c}\text { One-family } \\
\text { households } \\
\mathrm{m}^{2}\end{array}$ & $\begin{array}{c}\text { Extended-family households } \\
\mathrm{m}^{2}\end{array}$ & $\begin{array}{c}\text { Multi-person no family households } \\
\mathrm{m}^{2}\end{array}$ \\
\hline State-owned housings & $1.740 .155,5$ & 99,5 & 99,5 & 99,5 & 99,5 \\
\hline Housing result of assignment & $1.740 .155,5$ & 33,21 & 99,24 & 125,65 & 96,41 \\
\hline
\end{tabular}

\section{RESULTS AND DISCUSSION}

In a world where earthquakes are always present and at least a few major earthquakes occur every year, this engineering-based study sought to contribute to the research field of post-disaster relief. The study applied basic AHP and mathematical modeling to determine a more effective distribution of permanent housing to 
earthquake victims. AHP was used to allow families to priorities of the features of new housing. Price fell behind the size criterion in rank due to the government's program to make the housing affordable both at the time of purchase and in the installment payments.

These preferences were used to construct a mathematical model to better allocate housing space. The results are summarized in Tab. 6 .

Instead of the government's standard $99.5 \mathrm{~m}^{2}$ for all family households, under the new model, housing size has been allocated as follows: one-person households receive $33.21 \mathrm{~m}^{2}$, one-family households receive $99.24 \mathrm{~m}^{2}$, extended-family households receive $125.65 \mathrm{~m}^{2}$, and multiperson, no family households receive $46.41 \mathrm{~m}^{2}$.

One-person households were reduced to $33.21 \mathrm{~m}^{2}$ of housing space, while the housing space for one-family households with an average of four people remained about the same. Notably, the housing space for extended-family households with an average of six people increased by approximately $30 \mathrm{~m}^{2}$, making the space much more livable. Finally, the housing space for multi-person, no family households, with an average of two people decreased by approximately $53 \mathrm{~m}^{2}$.

When the distribution of families living in Van is evaluated according to family type, one-family households account for the largest percentage of the housing need at 65 $\%$. The next largest group is extended-family households at $24 \%$. Our mathematical modeling resulted in no meaningful change in the housing space for one-family households, but the housing space for extended-family households increased by $30 \mathrm{~m}^{2}$.

When the aggregate number of changes to housing space is assessed (both increases and decreases), the importance of implementing this model becomes apparent.

This mathematical model can be further refined by taking into account additional household factors, such as the number of children, elderly, disabled, or patients receiving at-home care. Another aspect that can be factored into the model is the proximity of close relatives and friends. This feature is important for families, especially children, to be able to return to their regular social lives.

Previous studies in the literature have primarily focused on the construction and assignment of temporary housing as well as the transfer of victims to locations that are far away from where they live. In this context, the present study represents a significant breakthrough.

There are several reasons why research of this type has not been pursued. The lack of common standards for disaster management discourages systematic approaches. Economic conditions limit the amount of funding for disaster management policies. Geography and climate also present challenges.

The Republic of Turkey has adopted a people-oriented approach to disaster relief, resulting in housing being distributed to families in exchange for low payments and interest-free installments spread out over 18 years.

\section{REFERENCES}

[1] Altay, N. \& Green, G. W. (2006). OR/MS research in disaster operations management. European Journal of Operational Research, 175, 475-493.

https://doi.org/10.1016/j.ejor.2005.05.016
[2] Galindo, G. \& Batta, R. (2013). Review of recent developments in OR/MS research in disaster operations management. European Journal of Operational Research, 230, 201-211. https://doi.org/10.1016/j.ejor.2013.01.039

[3] Number of family types (2016). http://www.tuik.gov.tr/ UstMenu.do?metod=temelist

[4] Hasanzadeh, H. \& Bashiri, M. (2016). An efficient network for disaster management: Model and solution. Applied Mathematical Modelling, 40(5-6), 3688-3702. https://doi.org/10.1016/j.apm.2015.09.113

[5] Najafi, M., Eshghi, K., \& Dullaert, W. (2013). A multiobjective robust optimization model for logistics planning in the earthquake response phase. Transportation Research Part E, 49, 217-249. https://doi.org/10.1016/j.tre.2012.09.001

[6] Rakes, R. R., Deane, K. J., Rees, P. L., \& Fetter, M. G. (2014). A desicion support system for post-disaster interim housing. Decision Support Systems, 66, 160-169. https://doi.org/10.1016/j.dss.2014.06.012

[7] Galarce, P. F., Canales, J. L., Vergara, C., \& Vejar, C. A. (2017). An optimization model for the location of disaster refuges. Socio-Economic Planning Sciences, 59, 56-66. https://doi.org/10.1016/j.seps.2016.12.001

[8] Gregorio, D. T. L. \& Soares, P. A. C. (2017). Post-disaster housing recovery guidelines for development countries based on experiences in the American continent. International Journal of Disaster Risk Reduction, 24, 340347. https://doi.org/10.1016/j.ijdrr.2017.06.027

[9] Joshi, A., \& Nishimura, M. (2016). Impact of disaster relief policies on the cooperation of residents in a post-disaster housing relocation program: A case study of the 2004 Indian Ocean Tsunami. International Journal of Disaster Risk Reduction, 19, 258-264. https://doi.org/10.1016/j.ijdrr.2016.08.018

[10] Dikmen, N. \& Ozkan, E. T. S. (2016). Housing after disaster: A post occupancy evaluation of a reconstruction project. International Journal of Disaster Risk Reduction, 19, 167178. https://doi.org/10.1016/j.jdrr.2016.08.020

[11] Othman, H. S. \& Beydoun, G. (2016). A metamodel-based knowledge sharing system for disaster management. Expert Systems with Applications, 63, 49-65. https://doi.org/10.1016/j.eswa.2016.06.018

[12] Fikar, C., Gronalt, M., \& Hirsch, P. (2016). A decision support system for coordinated disaster relief distribution. Expert Systems with Applications, 57, 104-116. https://doi.org/10.1016/j.eswa.2016.03.039

[13] Onan, K., Ülengin F., \& Sennaroğlu, B. (2015). An evolutionary multi-objective optimization approach to disaster waste management: A case study of Istanbul, Turkey. Expert Systems with Applications, 42, 8850-8857. https://doi.org/10.1016/j.eswa.2015.07.039

[14] Labib, A. \& Read, M. (2015). A hybrid model for learning from failures: The Hurricane Katrina disaster. Expert Systems with Applications, 42, 7869-7881. https://doi.org/10.1016/j.eswa.2015.06.020

[15] Zhang, B., Li, X., \& Wang, S. (2015). A novel case adaptation method based on an improved integrated genetic algorithm for power grid wind disaster emergencies. Expert Systems with Applications, 42, 7812-7824. https://doi.org/10.1016/j.eswa.2015.05.042

[16] Raikes, J. \& McBean, G. (2016). Responsibility and liability in emergency management to natural disasters: A Canadian example. International Journal of Disaster Risk Reduction, 16, 12-18. https://doi.org/10.1016/j.jjdrr.2016.01.004

[17] Erd, M., Schaeffer, F., Kostic, M., \& Reindl, M., L. (2016). Event monitoring in emergency scenarios using energy efficient wireless sensor nodes for the disaster information management. International Journal of Disaster Risk Reduction, 16, 33-42. https://doi.org/10.1016/j.jjdr.2016.01.001

[18] Silovs, M., Malahova, J., Levins, J., Jemeljanovs, V., \& Ketners, K. (2015). Wind-related disasters management and 
prevention improvement strategy. Procedia - Social and Behavioral Sciences, 213, 516-520.

https://doi.org/10.1016/j.sbspro.2015.11.443

[19] Wex, F., Schryen, G., Feuerriegel, S., \& Neumann, D. (2014). Emergency response in natural disaster management: Allocation and scheduling of rescue units. European Journal of Operational Research, 235, 697-708. https://doi.org/10.1016/j.ejor.2013.10.029

[20] Caymaz, E., Akyon, F. H., \& Erenel, F. (2013). A model proposal for efficient disaster management: the Turkish sample. Procedia - Social and Behavioral Sciences, 99, 609618. https://doi.org/10.1016/j.sbspro.2013.10.531

[21] Akkaya, G., Turanoğlu B., \& Öztaş S. (2015). An integrated fuzzy AHP and fuzzy MOORA approach to the problem of industrial engineering sector choosing. Expert System with Applications. 42, 9565-9573. https://doi.org/10.1016/j.eswa.2015.07.061

[22] Saaty, T. L. (1980). Marketing application of the analytic hierarchy process. Management Science, 26(7), 641-658. https://doi.org/10.1287/mnsc.26.7.641

\section{Contact information:}

Sinan ÖZTAŞ, PhD Student, Research Assistant

(Corresponding Author)

Department of Industrial Engineering,

Industrial Engineering Department of Ataturk University,

Yakutiye, Erzurum, 25240, Turkey

sinanoztas@atauni.edu.tr

\section{Gökay AKKAYA, Assistant Professor}

Department of Industrial Engineering

Industrial Engineering Department of Ataturk University,

Yakutiye, Erzurum, 25240, Turkey

gakkaya@atauni.edu.tr 